\title{
Research on Technology Innovation Performance Evaluation Model of Scientific and Technical Talents
}

\author{
Yun-Mei Li ${ }^{1, a,{ }^{*}}$, Qiao Liu ${ }^{2, b}$, Li-Juan Zhu ${ }^{3, c}$, Hong Qian ${ }^{4, d}$ \\ ${ }^{1}$ Center for industrial policy and management research, Wuhan University of Science and \\ Technology, 123-116-2, Gangdu Garden, Qingshan District, Wuhan, China \\ aymwust@163.com, 'bliuqiaowust@163.com \\ ${ }^{*}$ Corresponding author
}

Keywords: Scientific and technical talents, Technology innovation, Performance evaluation.

\begin{abstract}
With the rapid development of science and technology in the international environment, technology innovation has become the main orientation of the enterprise strategic development. Enterprise technology innovation to a large extent is determined by innovation performance of scientific and technical talents, which is difficult to be quantified and objectively evaluated. Therefore, it is of great significance to construct a fair, comprehensive and reasonable performance evaluation model. The author measures innovation performance of scientific and technical talents from three dimensions: technical evaluation, economic evaluation and strategic evaluation. Evaluation indexes are selected from aspects of operability, motivation, and strategy. Meanwhile, formulas are used to quantify the innovation performance of scientific and technical talents. The model will ensure the relative fairness in performance evaluation, which then provokes scientific and technical talents to be devoted to efficient and creative research work in science and technology. It provides abundant stimulation for original and long-term independent of enterprise innovation.
\end{abstract}

\section{Introduction}

Nowadays, technology innovation performance evaluation has been widely used in domestic and foreign technology innovation management activities. Domestic research in science and technology innovation performance evaluation is confined to the evaluation of innovation capability features. The quantitative analysis for innovation performance is still in the conceptual and theoretical stage. However, foreign scholars have done a deeper research on aspects such as talents measurement, assessment of scientific and technical achievements, and performance evaluation of knowledge workers. Their research provides certain reference for Chinese enterprises to objectively and fairly evaluate innovation performance of scientific and technical talents. But their research still has defects. For example, the evaluation dimensions are not comprehensive; the evaluation index is not operational; weight distribution of the index is not reasonable. Faced with the questions above, the author has put forward a technology innovation performance evaluation model of scientific and technical talents. We can accumulate, quantify and objectively evaluate the innovation performance of science and technology talents by putting the model into practice.

\section{The Innovation Performance Evaluation Model of Scientific and Technical Talents}

\section{Model Construction}

Innovation performance of scientific and technical talents can be evaluated in many ways. Some evaluations are based on results. For example, Robert Szakonyi finds that universities and research institutes often evaluate their researchers using indexes such as patents, published articles and monographs, and citation frequency of literature. But enterprises, which pursue profits and cost control, do not attach much importance to these indexes that have little association with their business goals. Some evaluations are based on behaviors. For instance, J.C.Flanagan proposes critical incident method, rating scale method and behavior anchor method. Other evaluations are based on competency. For example, Klaus indicates that performance evaluation of knowledge workers should include six personal qualities and ten cognitive abilities. 
By literature analysis, interview and investigation, three dimensions of technology innovation performance have been determined. They are technical evaluation, economic evaluation and strategic evaluation. Technical evaluation mainly measures the advance of technology innovations. Economic evaluation mainly measures economic benefits created by technology innovations. Strategic evaluation is to measure the contribution technology innovations have made to enterprise technology progress. Each dimension is divided into several secondary indexes or third class indexes. The innovation performance evaluation model of scientific and technical talents is shown in Figure 1 (assuming that there are $\mathrm{n}$ types of achievements, s key innovations, $\mathrm{m}$ science and technology talents to be evaluated).

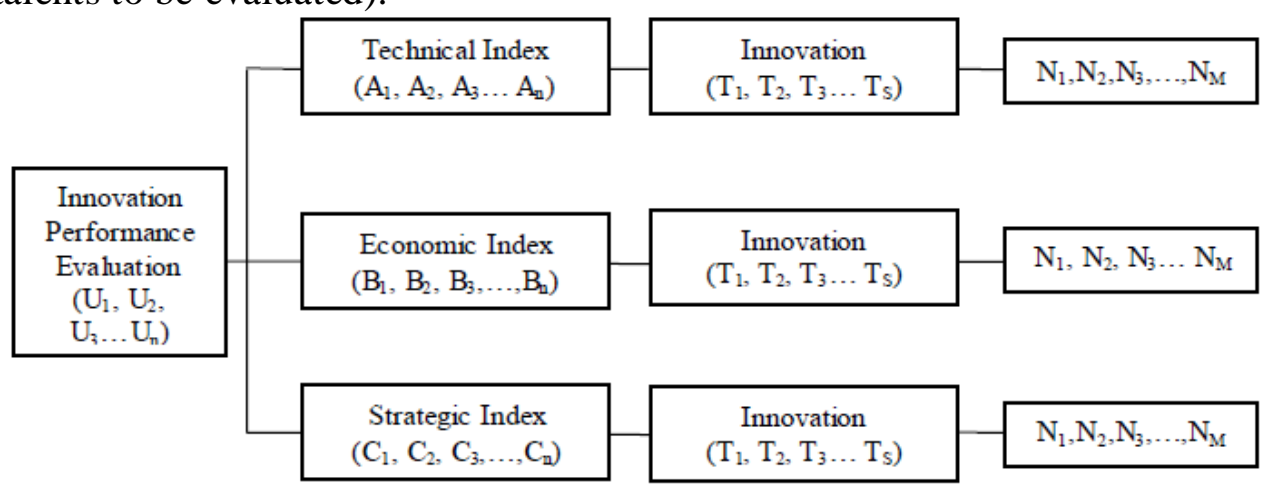

Fig.1 The Innovation Performance Evaluation Model of Scientific and Technical Talents

\section{Index Selection Principles}

In the model mentioned above, each dimension is divided into several secondary indexes, the selection of which is in accordance with corporate real situation. Principles for selecting indexes are as follows. First, they should be operational. Second, they should reflect the nature of a team. Third, duplication of indexes should be avoided. Fourth, they should be strategy-orientated. Fifth, they should be incentive. Based on the principles above, the author has summarized the evaluation indexes of the model after doing literature research. The indexes are listed in Table 1 above.

Tab.1 Innovation Performance Evaluation Indexes of Scientific and Technical Talents

\begin{tabular}{|c|c|c|}
\hline $\begin{array}{l}\text { Types of } \\
\text { Evaluation }\end{array}$ & Evaluation Dimensions & Evaluation Indexes \\
\hline \multirow{8}{*}{$\mathrm{U}_{1}$} & \multirow{3}{*}{ Technology Evaluation $\mathrm{A}_{1}$} & The Extent of Innovation $\mathrm{A}_{11}$ \\
\hline & & Project Size and Complexity $\mathrm{A}_{12}$ \\
\hline & & The Advance of Key Technologies $\mathrm{A}_{13}$ \\
\hline & \multirow[t]{2}{*}{ Economic Evaluation $\mathrm{B}_{1}$} & Direct Economic Benefits $\mathrm{B}_{11}$ \\
\hline & & Indirect Economic Benefits $\mathrm{B}_{12}$ \\
\hline & \multirow{3}{*}{ Strategic Evaluation $C_{1}$} & Technical Radiation $\mathrm{C}_{11}$ \\
\hline & & $\begin{array}{l}\text { The Conformity With Enterprise Technology Innovation Development } \\
\text { Strategy } C_{12}\end{array}$ \\
\hline & & The Correlation With the Enterprise's Main Business $\mathrm{C}_{13}$ \\
\hline \multirow{7}{*}{$\mathrm{U}_{2}$} & \multirow{3}{*}{ Technology Evaluation $\mathrm{A}_{2}$} & The Extent of Technical Innovation $\mathrm{A}_{21}$ \\
\hline & & Technology Advancement $\mathrm{A}_{22}$ \\
\hline & & Competitiveness in the Technology Innovation Market $\mathrm{A}_{23}$ \\
\hline & \multirow[t]{2}{*}{ Economic Evaluation $\mathrm{B}_{2}$} & Direct Economic Benefits $\mathrm{B}_{21}$ \\
\hline & & Indirect Economic Benefits $\mathrm{B}_{22}$ \\
\hline & \multirow[t]{2}{*}{ Strategic Evaluation $\mathrm{C}_{2}$} & Technical Radiation $\mathrm{C}_{21}$ \\
\hline & & The Correlation with the Enterprise's Main Business $\mathrm{C}_{22}$ \\
\hline \multirow{5}{*}{$\mathrm{U}_{3}$} & \multirow[t]{2}{*}{ Technology Evaluation $A_{3}$} & Applicability of Technology $\mathrm{A}_{31}$ \\
\hline & & Substitutability of Technology $\mathrm{A}_{32}$ \\
\hline & \multirow[t]{2}{*}{ Economic Evaluation $\mathrm{B}_{3}$} & Direct Economic Benefits $\mathrm{B}_{31}$ \\
\hline & & Indirect Economic Benefits $\mathrm{B}_{32}$ \\
\hline & Strategic Evaluation $\mathrm{C}_{3}$ & The Correlation with the Enterprise's Main Business $C_{31}$ \\
\hline \multirow{5}{*}{$\mathrm{U}_{4}$} & \multirow{2}{*}{ Technology Evaluation $\mathrm{A}_{4}$} & The Advance of Key Technologies $\mathrm{A}_{41}$ \\
\hline & & Competitiveness in the Technology Innovation Market $\mathrm{A}_{42}$ \\
\hline & \multirow[t]{2}{*}{ Economic Evaluation $\mathrm{B}_{4}$} & Direct Economic Benefits $\mathrm{B}_{41}$ \\
\hline & & Indirect Economic Benefits $\mathrm{B}_{42}$ \\
\hline & Strategic Evaluation $\mathrm{C}_{4}$ & The Correlation with the Enterprise's Main Business $\mathrm{C}_{41}$ \\
\hline
\end{tabular}




\section{Index Weight Determination}

Both qualitative and quantitative methods are applied to distribute weights. Cumulative score is chosen to reflect evaluation result of a talent's innovation performance. Evaluation methods such as Delphi method, analytic hierarchy process (AHP), scale rating method and order relation analysis method are often used when distributing weights. The calculating process and results are as follows:

Firstly, calculate weight distribution of each evaluation dimension. According to Delphi method, we deduce that technical indexes and economic indexes are of equal importance, and that strategic indexes are more important compared with the previous two. By means of AHP, we calculate weight of each index hierarchy and use Matlab to measure consistency of the judgement matrix, as shown in Table 2.

Tab.2 The Evaluation Index Weight Coefficient of Scientific and Technical Achievements

\begin{tabular}{|c|c|c|c|c|}
\hline Scientific and Technical Achievements & $\begin{array}{c}\text { Technical } \\
\text { Index }\end{array}$ & $\begin{array}{c}\text { Economic } \\
\text { Index }\end{array}$ & $\begin{array}{c}\text { Strategic } \\
\text { Index }\end{array}$ & $\omega_{\mathrm{i}}$ \\
\hline Technical Index & 1.0000 & 1.0000 & 2.0000 & 0.3802 \\
\hline Economic Index & 1.0000 & 1.0000 & 2.0000 & 0.3802 \\
\hline Strategic Index & 0.5000 & 0.5000 & 1.0000 & 0.2396 \\
\hline
\end{tabular}

The consistency ratio $\mathrm{CR} \approx 0.0000<0.1000$, so we can judge that the matrix has the consistency with overall satisfaction.

Secondly, based on the methods above, calculate the weight distribution of different innovations, as shown in Table 3.

Tab.3 The Weight Coefficient of the Performance Evaluation Index

\begin{tabular}{|c|c|c|c|c|c|}
\hline Performance Evaluation & $\mathrm{U}_{1}$ & $\mathrm{U}_{2}$ & $\mathrm{U}_{3}$ & $\mathrm{U}_{4}$ & $\omega_{\mathrm{i}}$ \\
\hline $\mathrm{U}_{1}$ & 1.0000 & 3.0000 & 2.0000 & 3.0000 & 0.5378 \\
\hline $\mathrm{U}_{2}$ & 0.3333 & 1.0000 & 0.6667 & 1.0000 & 0.1244 \\
\hline $\mathrm{U}_{3}$ & 0.5000 & 1.5000 & 1.0000 & 1.5000 & 0.2134 \\
\hline $\mathrm{U}_{4}$ & 0.3333 & 1.0000 & 0.6667 & 1.0000 & 0.1244 \\
\hline
\end{tabular}

The consistency ratio $\mathrm{CR} \approx 0.0000<0.1000$, so we can judge that the matrix has the consistency with overall satisfaction.

Finally, according to the previous results, we can get the index weight of innovation performance evaluation, as shown in Table 4.

Tab.4 Index Weight of Innovation Performance Evaluation

\begin{tabular}{|c|c|c|c|c|}
\hline The First Hierarchy & \multicolumn{2}{|c|}{ The Second Hierarchy } & \multicolumn{2}{c|}{ The Third Hierarchy } \\
\hline \multirow{4}{*}{$\begin{array}{c}\text { Innovation Performance } \\
\text { Evaluation }\end{array}$} & $\mathrm{U}_{1}$ & 0.5378 & $\mathrm{~A}_{1}$ & Weight \\
\cline { 4 - 5 } & & & $\mathrm{B}_{1}$ & 0.3802 \\
\cline { 4 - 5 } & & & $\mathrm{C}_{1}$ & 0.3802 \\
\cline { 4 - 5 } & $\mathrm{U}_{2}$ & 0.2134 & $\mathrm{~A}_{2}$ & 0.2396 \\
\cline { 4 - 5 } & & & $\mathrm{B}_{2}$ & 0.3802 \\
\cline { 4 - 5 } & & & $\mathrm{C}_{2}$ & 0.3802 \\
\cline { 4 - 5 } & $\mathrm{U}_{3}$ & 0.1244 & $\mathrm{~A}_{3}$ & 0.2396 \\
\cline { 4 - 5 } & & & $\mathrm{B}_{3}$ & 0.3802 \\
\cline { 4 - 5 } & & & $\mathrm{C}_{3}$ & 0.3802 \\
\cline { 4 - 5 } & $\mathrm{U}_{4}$ & 0.1244 & $\mathrm{~A}_{4}$ & 0.2396 \\
\cline { 4 - 5 } & & & $\mathrm{B}_{4}$ & 0.3802 \\
\cline { 4 - 5 } & & & $\mathrm{C}_{4}$ & 0.3802 \\
\hline
\end{tabular}

\section{Scoring Criteria}

The innovation performance results of scientific and technical talents are presented by scoring. Therefore, qualitative indexes should be quantified so that innovation performance can be quantified by scoring.

From the previous analysis, we know each evaluation dimension is divided into several evaluation indexes and should set corresponding criteria for each evaluation index. Based on results of the research, the evaluation standard scores range from 0 to 5 points. There are four levels. The 
fourth level, namely the top level, whose score ranges from 4 to 5 points; the score of third level is 3 points; the score of second level ranges from 1 to 2 points; the score of first level is 0 point, namely the lowest level. The top level indicates the innovation performance is good and the lowest level indicates the innovation performance is the poorer.

\section{The Score Accumulation Method and Formula of Innovation Performance}

After index weight in each hierarchy and scoring criteria are determined respectively, we classify and mark all the innovations of scientific and technical talents, so as to get single score of each kind of innovation. The calculation formula is as the follow:

$\mathrm{T}_{\mathrm{i}}=\left(\Sigma \mathrm{A}_{\mathrm{i}} \mathrm{X}_{\mathrm{i}}+\Sigma \mathrm{B}_{\mathrm{i}} \mathrm{Y}_{\mathrm{i}}+\Sigma \mathrm{C}_{\mathrm{i}} \mathrm{Z}_{\mathrm{i}}\right) *$ Individual Contribution Rate

In the formula, $T_{i}$ represents the final total score of the ith achievement for one person; $\Sigma A_{i} X_{i}$ represents the sum of the products of technical index weight and score. $\Sigma B_{i} Y_{i}$ and $\Sigma C_{i} Z_{i}$ are the same as $\Sigma A_{i} X_{i . ;}$ individual contribution rate stands for the contribution a talent makes in an achievement. It is determined by a talent's ranking in a team. Usually it is expressed by percentage.

After calculating a talent's single innovation score, we need to summarize all the innovations and get the personal composite score.

$\mathrm{N}_{1}=\mathrm{U}_{1} * \mathrm{~T}_{\mathrm{u} 1}+\mathrm{U}_{2} * \mathrm{~T}_{\mathrm{u} 2}+\mathrm{U}_{3} * \mathrm{~T}_{\mathrm{u} 3}+\mathrm{U}_{4} * \mathrm{~T}_{\mathrm{u} 4}$

In the formula, $\mathrm{N}_{1}$ represents the composite score of the first talent. $\mathrm{U}_{1} * \mathrm{~T}_{\mathrm{u} 1}$ represents the products of the first kind of innovation weight and score. And the later algorithm is the same.

\section{Empirical Research}

The author obtains relevant materials of scientific and technical talents after interview and survey in W Company. The materials mainly include original data of science and technology award and basic information of scientific and technical talents. By organizing the original data, we find 19786 valid data, among which there are 1730 major projects data in science and technology, 4439 patent data, 6958 data of science and technology progress award, and 6659 technical know-how data.

Tab.5 Scoring Results

\begin{tabular}{|c|c|c|c|c|c|}
\hline \hline \multicolumn{2}{|c|}{ Index } & \multirow{2}{*}{ Rank } & \multirow{2}{*}{$\mathrm{B}$} & $\mathrm{C}$ & \multirow{2}{*}{ Total Marks } \\
\hline \multirow{3}{*}{$\begin{array}{c}\text { Important Special Item in } \\
\text { Science and Technology }\end{array}$} & $\mathrm{R}_{1}$ & 5.7030 & 2.2812 & 1.9168 & 9.9010 \\
\cline { 2 - 5 } & $\mathrm{R}_{2}$ & 3.8020 & 3.0416 & 1.9168 & 8.7604 \\
\cline { 2 - 5 } & $\mathrm{R}_{3}$ & 2.6614 & 2.2812 & 0.7188 & 5.6614 \\
\hline \multirow{5}{*}{$\begin{array}{c}\text { Science and Technology } \\
\text { Progress Award }\end{array}$} & $\mathrm{R}_{1}$ & 5.7020 & 1.9010 & 1.1980 & 8.8020 \\
\cline { 2 - 5 } & $\mathrm{R}_{2}$ & 5.1327 & 1.7109 & 0.9584 & 7.8020 \\
\cline { 2 - 5 } & $\mathrm{R}_{3}$ & 4.3723 & 1.5208 & 0.8386 & 6.7317 \\
\cline { 2 - 5 } & $\mathrm{R}_{4}$ & 3.6119 & 1.1406 & 0.7188 & 5.4713 \\
\cline { 2 - 5 } & $\mathrm{R}_{5}$ & 2.8515 & 0.9505 & 0.4792 & 4.2812 \\
\cline { 2 - 5 } & $\mathrm{R}_{6}$ & 2.0911 & 0.7604 & 0.4792 & 3.3307 \\
\cline { 2 - 5 } & $\mathrm{R}_{7}$ & 1.7109 & 0.5703 & 0.3594 & 2.6406 \\
\cline { 2 - 5 } & $\mathrm{R}_{8}$ & 1.3307 & 0.5703 & 0.2396 & 2.1406 \\
\hline \multirow{3}{*}{ Patent } & $\mathrm{R}_{1}$ & 9.8852 & 1.9010 & 2.1564 & 13.9426 \\
\cline { 2 - 5 } & $\mathrm{R}_{2}$ & 6.2733 & 1.1406 & 1.3178 & 8.7317 \\
\cline { 2 - 5 } & $\mathrm{R}_{3}$ & 3.9921 & 0.7604 & 0.8386 & 5.5911 \\
\hline \multirow{3}{*}{ Technical Know-how } & $\mathrm{R}_{1}$ & 9.8852 & 1.9010 & 2.1564 & 13.9426 \\
\cline { 2 - 5 } & $\mathrm{R}_{2}$ & 6.2733 & 1.1406 & 1.3178 & 8.7317 \\
\cline { 2 - 5 } & $\mathrm{R}_{3}$ & 3.9921 & 0.7604 & 0.8386 & 5.5911 \\
\hline
\end{tabular}

In the process of sorting out the original data of science and technology award, we make grade classification for four innovations. The innovation of major projects is divided into three ranks. Science and technology progress award is divided into eight ranks. Both patent and technical know-how are divided into three ranks. According to the model and methods described above, a panel of experts use evaluation criteria table to grade each rank of major projects in science and technology, science and technology progress award, patent and technical know-how. Meanwhile, by combining with the weight coefficient of the technical index, economic index and strategic index, 
we can get the results as shown in Table 5 .

Taking advantage of order relation analysis method, we can obtain the weight coefficient and scores of each rank and each innovation, as shown in Table 6 and Table 7.

Tab.6 Weight Coefficient of Each Rank

\begin{tabular}{|c|c|c|c|c|}
\hline Innovation & $\begin{array}{c}\text { Important Special Item in } \\
\text { Science and Technology }\end{array}$ & $\begin{array}{c}\text { Science and Technology } \\
\text { Progress Award }\end{array}$ & Patent & Technical Know-how \\
\hline $\mathrm{R}_{1}$ & 0.4070 & 0.2136 & 0.4933 & 0.4933 \\
\hline $\mathrm{R}_{2}$ & 0.3602 & 0.1894 & 0.3089 & 0.3089 \\
\hline $\mathrm{R}_{3}$ & 0.2328 & 0.1634 & 0.1978 & 0.1978 \\
\hline $\mathrm{R}_{4}$ & - & 0.1328 & - & - \\
\hline $\mathrm{R}_{5}$ & - & 0.1039 & - & - \\
\hline $\mathrm{R}_{6}$ & - & 0.0808 & - & - \\
\hline $\mathrm{R}_{7}$ & - & 0.0641 & - & - \\
\hline $\mathrm{R}_{8}$ & - & 0.0520 & - & - \\
\hline
\end{tabular}

Tab.7 Scoring of Each Rank

\begin{tabular}{|c|c|c|c|c|}
\hline Innovation & $\begin{array}{c}\text { Important Special Item in } \\
\text { Science and Technology }\end{array}$ & $\begin{array}{c}\text { Science and Technology } \\
\text { Progress Award }\end{array}$ & Patent & Technical Know-how \\
\hline $\mathrm{R}_{1}$ & 100 & 100 & 100 & 100 \\
\hline $\mathrm{R}_{2}$ & 88.5 & 88.64 & 62.62 & 62.62 \\
\hline $\mathrm{R}_{3}$ & 57.2 & 76.48 & 40.10 & 40.10 \\
\hline $\mathrm{R}_{4}$ & - & 62.16 & - & - \\
\hline $\mathrm{R}_{5}$ & - & 48.64 & - & - \\
\hline $\mathrm{R}_{6}$ & - & 37.84 & - & - \\
\hline $\mathrm{R}_{7}$ & - & 30.00 & - & - \\
\hline $\mathrm{R}_{8}$ & - & 24.32 & - & - \\
\hline
\end{tabular}

Referring to the scores above, we can calculate innovation performance quantitative scores of each scientific and technical talent. Moreover, accumulation of quantitative scores can reflect sustainable contribution talents have made to enterprise. Judging by experts' experience in W Company, innovation performance evaluation result of scientific and technical talents is basically in accord with the fact. The result can also be used to pointedly develop or select scientific and technical talents, combining with strategic needs of W Company. Therefore, technology innovation performance evaluation model of scientific and technical talents is feasible and applicable.

\section{Summary}

Technology innovation performance evaluation model of scientific and technical talents is on the basis of literature analysis, investigation and interview. Practical cases have proved the model is feasible. The model provides reference for Chinese enterprises to objectively and fairly evaluate the innovation performance of scientific and technical talents, which will largely improve their innovation enthusiasm and strengthen their initiative. Meanwhile, the model also offers evidence for the evaluation, screening, selection and training of scientific and technical talents in the enterprises.

\section{Acknowledgement}

This research was financially supported by the Research Project of Humanities and Social Sciences in the Education Department of Hubei Province (14D008) and Graduate Student Teaching Research Project in Wuhan University of Science and Technology (Yjg201424).

\section{References}

[1] F.B Lv. How to Improve Science and Technology Talents Innovation Ability of Small and Medium-Enterprises. Economy and Management, 2010, 24(5); 60-63. 
[2] Y Qi, J.X Wei, J Wang. Research on the performance evaluation of Jiangsu Province science and technology talents development. Science and Technology Management Research, 2015, 35(5); 68-73.

[3] Y.C Fang [1], T.G Huang [2]. Experience Reference of International Creative enterprise science and technology talents development system_- based on the research in America, German and Kerea. Science Research Management, 2013, 0(S1); 230-235.

[4] X.N Wang, Y.M Huang, Q.C He. The Application of TOPSIS Method and Neural Network in Performance Evaluation of Health Science and Technology Talents Scientific Research. Science and Technology Progress and Policy, 2005, 22(8); 34-36.

[5] Corey E. Miller, Carl L.Thornton. How Accurate Are Your Performance Appraisals [J].Public Personnel Management, 2006, 35(20).

[6] Walter G. Tymon Jr.,Stephen A. Stumpf, Jonathan P. Doh. Exploring talents management in India:The neglected role of intrinsic rewards [J].Journal of World Business,2010(45).

[7] Bobert Szakonyi. Measuring R\&D Effectiveness [J]. Research Technology Measurement, 1994(5-6).

[8] Klaus Moser, Heinz Schuler, Uwe Funke. The moderating effect of raters' opportunities to observe ratees' job performance on the validity of an assessment center [J].International Journal of Selection and Assessment, 1999, 7(3).

[9] Z.Z Xiang, K.J Liao, Q.H Liu: Simple And Easy Method of Determining Maturity Evaluation Index Weight Based on the Order Relation [J]. Journal Guangxi University (Natural Science Edition), 2009, 34(6). 